\title{
Theoretical foundations of the institutional support for the innovative development of tourist sports and entertainment destinations
}

\author{
Ksenia Derevianko ${ }^{1}$, Irina Obraztsova $^{1}$, Victoria Orlovskaya ${ }^{2, *}$, and Inga Filippova ${ }^{1}$ \\ ${ }^{1}$ Saint-Petersburg University of Management Technologies and Economics, Lermontovsky pr., 44, \\ 190103 Saint-Petersburg, Russia \\ ${ }^{2}$ Saint-Petersburg State University of Economics, Sadovaya str., 21, 191023 Saint-Petersburg, Russia
}

\begin{abstract}
The article examines the essence of tourism and sports as independent socio-economic systems and as subsystems of a higher order the economy of the state, and on this basis, the authors' concept of institutional approaches to the formation of the system structures of organizational and economic models of their development is proposed, taking into account the sectoral clustering in the creation of tourist sports and entertainment destinations and recreational complexes.
\end{abstract}

\section{Introduction}

Being the phenomena of our time, tourism and sports, as social categories, are closely interconnected not only by the essence of the fact that they are elements of the philosophical category of culture, but also by the fact that they are based on society, and the directions of these activities are seriously intertwined and closely interrelated. And what is especially important: tourism and sports, complementing each other, represent a single social space with health care, for example, in the implementation of the Federal Program of the Russian Federation "Health of the Nation". All categories of the population are actively and passively included in the processes of tourism and sports. On the one hand, governments and the private sector bear multibillion-dollar costs for the development of tourism and sports and the formation of their infrastructure, and on the other hand, they receive significant revenues from the sale of tourism and sports services, television broadcasts of sports events and their advertising, etc. At the same time, both tourism and sports, being the socio-economic structures of the state, function in the system of market relations in accordance with the principles of the World Trade Organization.

And here the numerous contradictions arise: this is how a professional athlete is presented on the market as a commodity, at the same time being both fixed assets, and an object of labour, and labour force as a producer of newly created value of goods (services).

In tourism, the individual acts in two hypostases - as a productive force and as a consumer of the directly adapted labour result, which leaves a special imprint on the

\footnotetext{
*Corresponding author: author@email.org
} 
formation and consideration of fundamental social constants in the process of managing society and man.

The training of highly qualified athletes and the management of sports and entertainment events require appropriate forms and methods of organization and management. This entails the creation of a system of related organizational services.

Sports facilities built for competitions (from the Olympic Games to championships of sports federations) become the core of the formation of regional sports and entertainment and sports and recreation complexes. Moreover, persons who came to a sports destination to get acquainted with the achievements of athletes and subsequent recreation on its territory (which are the main source of income for the complex) can be classified as both visitors and tourists. This is another economic contradiction between the sectors "Sport" and "Tourism", which requires resolution already at the legislative level and leaves a certain imprint on the management system.

Similar questions arise in the course of sports and recreational activities. Moreover, depending on the type of sport and the systems of sports recreation of tourists, the categories of persons participating in it, when solving organizational issues, it becomes necessary to take into account the specifics of specialization. At the same time, special requirements for the provision of tourist and sports services of all types to persons with disabilities and participating in adaptive sports are an important organizational regulator. All this allows us to recognize that the sports management industry (like the tourism industry) acts as a complex and dynamically developing socio-economic system, which is based on society, both at the level of a professional athlete and a visitor to a sports and entertainment event.

The specificity of the process of creating tourism and sports services provides for the search for institutional development of industries through simulation and dynamic modelling of management systems at the domestic level and in interstate markets. At the same time, the reform process involves the development of fundamentally new forms and methods of managing the development of tourism and sports, starting with the study of the methodological features of the organizational and economic regulation of the industry, both at the federal and regional levels, and ending with the development of a system of educational trajectories in training staff for sectoral economies.

\section{Materials and methods}

The article uses the methods of analysis and synthesis, comparison and generalization, which made it possible to identify the main trends in the change in the role of system of "Sport and physical recovery of a person", to establish a dialectical connection between sports and tourism, trends in the development and attractiveness of sports and entertainment destinations. The informational basis of the research is formed by regulatory legal acts, the works of domestic and foreign scientists, practitioners in the field of sports and tourism management, the economy of impressions and Internet resources.

\section{Results and discussion}

The system "Sport and physical recovery of a person" becomes a full-fledged member of the open international market for goods and services, the organizational and economic model of which is presented by us in Fig.1. It should be noted that from our point of view, buildings and sports facilities of all forms and types, sports equipment are an integral part of the sports and physical health industry and should be considered as an element of the industry market. 
The main element of this system and its core is the athlete, who acts simultaneously as a "subject of labour" and "means of production", which leads to numerous contradictions both in the field of scientific understanding of the economic essence of the formation and implementation of sports services, and in the practical implementation of the labour process. An athlete can even be considered as "basic production assets» because he, constantly wearing out, transfers part of "his value" to sports services that the spectator buys.

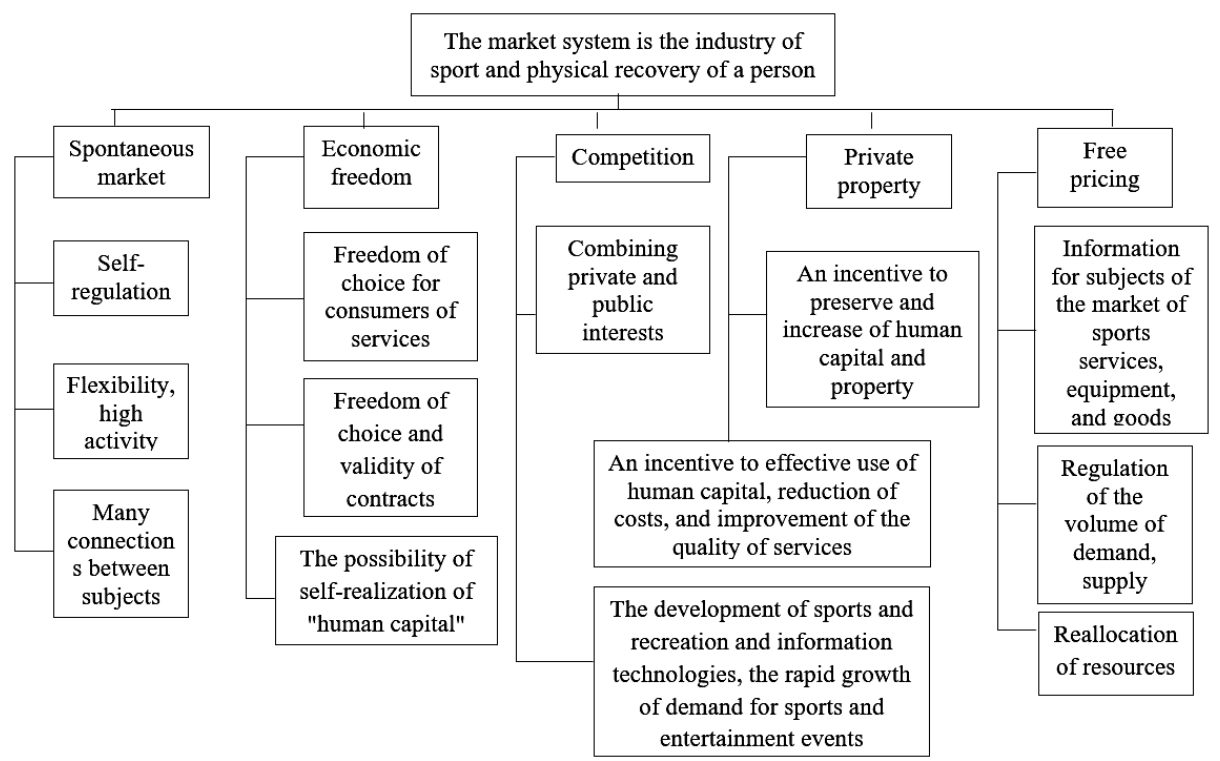

Fig. 1. Organizational and economic model of the market system of sports and physical recovery of a person

The system is, as is known, a set of interconnected elements that are in close interconnection with each other and represent some holistic formation, different in its properties from the elements included in it [1].

Considering the system "Sports and physical recovery of a person", it should be noted that it is built on the basis of the general theory of management of socio-economic systems; logically generalizes the experience and social practice of the development of the regional foundations for the production of sports and recreational services; operates on the basis of general systemic and special subject principles developed in the construction of a similar system in the tourism industry; is guided by a single concept that defines the goals, objectives and main content of management, as well as requirements for the end result of the industry's functioning - ensuring the health of the nation.

Innovative principles for the development of the Russian economy determine the directions of reforming the socio-economic system " Sports and physical recovery of a person " both in the context of the industry-specific sports orientation, and the functioning of regional management complexes and tourist destinations.

The development of the institutional environment for the functioning of the market mechanism, both in the economy as a whole and in its individual subsystems, allows it to work effectively with social consequences. The behaviour of business entities, the operation of the laws of supply and demand, the dynamics of economic growth, the functioning of market and administrative mechanisms - all these and other phenomena and processes depend on the institutions adopted in a society. The creation of effective regional institutions is necessary for the emergence of a regulatory framework for economic 
planning and the functioning of market mechanisms, as well as for the implementation of targeted socio-economic and financial policies in the localities. Therefore, there is a need for institutional support of innovation processes, which contributes to a qualitative change in economic systems [2-4].

The region is an extremely complex management system, consisting of relatively independent systems: economic, political, social, spiritual, cultural and others, each of which performs specific functions. In these systems, sectoral subsystems arise that are formed on a territorial basis and represent the corresponding destinations. These include a sports and entertainment destination (SED).

Sport is at the same time a subsystem of the region and an independent large open system that interacts with all the socio-economic and political processes of the region, on the territory of which its facilities are located, and the corresponding infrastructure is formed [5].

The functioning of the most significant SED should be coordinated by specially created organizations: destination marketing management organization (DMO) or convention and visitor's bureau (CVB) [6]. These destinations are formed by the concentration of various services and facilities aimed at meeting the needs of visitors (including sports fans). In most cases, sports and entertainment destinations are a combination of the following four components:

- sports event (attractions);

- accessibility - local transport;

- amenities - means of accommodation, food, entertainment, trade and other services;

- ancillary services - DMO, CVB.

For the successful work of a sports and entertainment destination, it is necessary to have all these components, which must be combined in a variety of ways in a variety of cultural, socio-economic and natural conditions of existing destinations [7]. In terms of identification, they have common features:

- represent sporting value;

- they are inseparable, since the sports and entertainment product is consumed by the fan (visitors to the competition) in the same place where it is produced, and in order to experience the experience, it must be physically present at the destination;

- used not only by sports fans, but also by the local population and other visitors;

- their various elements complement each other.

Representing an integral functional system, a sports and entertainment destination has different purposes and functions, taking into account the methodological approach of $\mathrm{Z}$. Kamilova: economic (supply, demand, activity, specialization of the region, regional management); demographic; ecological; social [8].

The development of the system "Sports and physical health improvement of a person" in the region through the formation of SED is closely related to the entire structure of the potential of the region. The key ones include those whose formation and development can ensure the sustainable functioning and development of the region. These potentials are formed under the influence of needs, which dictate the degree of use of the potential of opportunities. It is the potential of needs that is the source and driving force for the development of sports and sports improvement of the population in the region; all other potentials should be oriented towards it. Obviously, the visitors (sports fans) are the central link forming the general potential of needs.

The formation of the institutional environment for the innovative development of SED is influenced by economic, social, demographic and geographic factors, which determines the specifics of the institutional regional environment [9]. Formed under the influence of various factors, the institutional environment determines the perception and behaviour of economic agents (Fig. 2). 


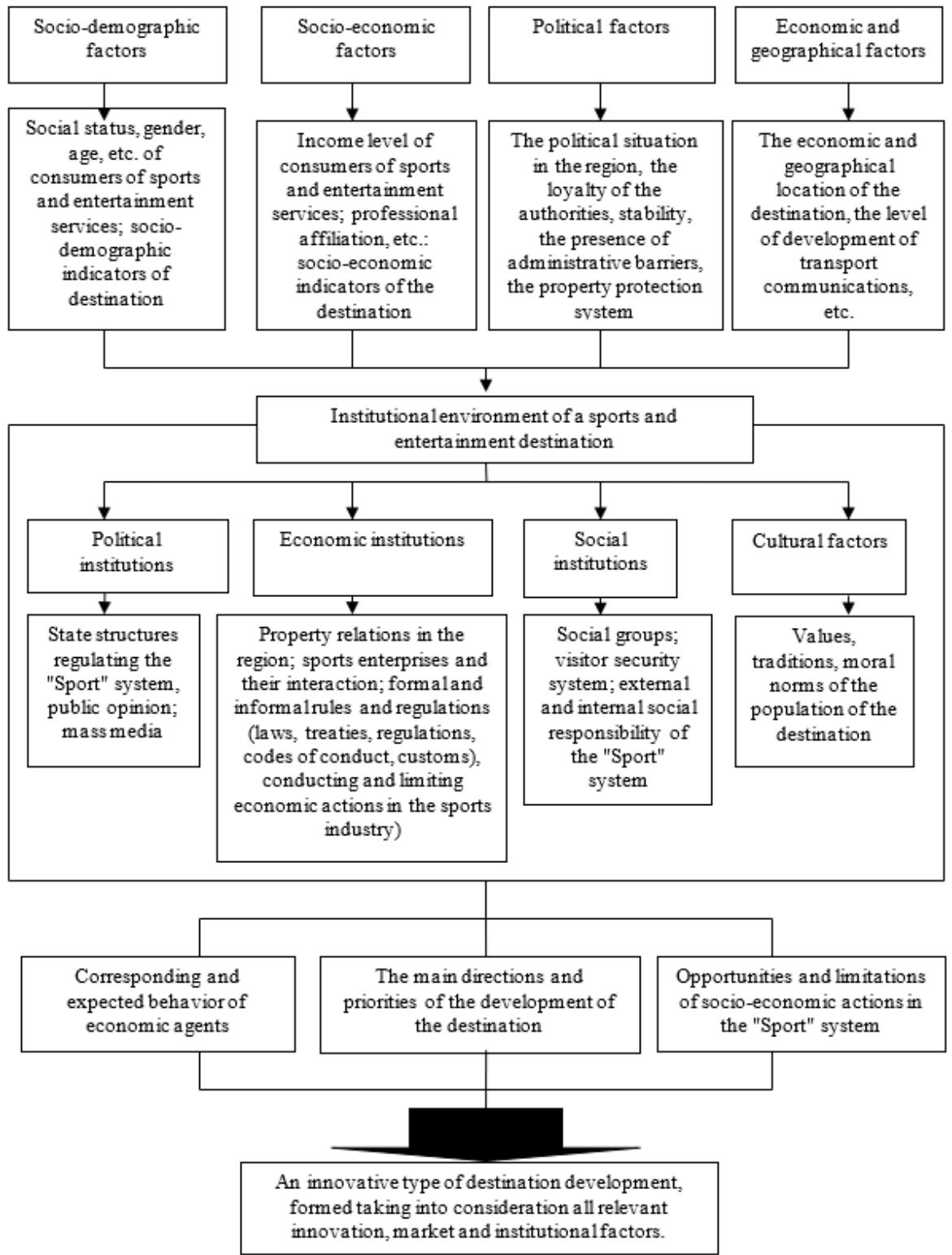

Fig. 2. The impact of the institutional environment on the development of a sports and entertainment destination

The innovative development of SED is impossible without an adequately formed institutional support, which should have:

- developed regulatory framework;

- orderly property relations, taking into account the peculiarities of sports and entertainment activities (the development of which may entail both positive and negative consequences for the population);

- brought in full compliance with federal, regional and local programs for the development of sports;

- improved infrastructure of the "sport" system; 
- a mechanism for the effective use, maintenance and restoration of recreational resources;

- developed information and statistical structure of the "sport" system;

- an effective system of training, retraining and advanced training of personnel, taking into account the industry specifics;

- state support for socially significant sports and adaptive sports;

- improvement of the mechanism of public-private partnership.

Determination of state policy in relation to the development of SED allows to comprehensively solve its economic problems. Moreover, the development and implementation of state programs for the development of SED at all levels allow more efficient use of limited financial and material and technical resources, to implement the strategic goals of development of SED. An example is the creation in Russia of eleven sports and entertainment destinations (SPD) according to the "Program of the 2018 FIFA World Cup". Consequently, ensuring the economic development of the SED as a subsystem of the national economic complex is an important political task that requires special attention from federal, regional and municipal authorities.

The formation of sports and entertainment destinations in the system "Sports and physical health improvement of a person" will certainly contribute to the development of institutional relations at the regional level and the creation of fundamentally new institutions for managing the socio-economic complexes of the state.

In turn, the entry of the Russian Federation into the World Trade Organization (WTO) covers almost all sectors of the state's economy. The sports industry is no exception. A special place in it is occupied by the system of design and construction of sports facilities, as well as the organization of their subsequent operation. And if the issues of improving the preparation of design estimates and the implementation of quality control of construction and installation work are solved by a simple transition to the use of generally recognized world standards, then the system for organizing the subsequent operation of sports facilities requires close attention. This is especially true for the "new" for Russia types of sports activities, which is auto-motor sports [7].

With the advent of motorsport, it has become one of the most popular types of sports performances. Many countries host races in dozens of different classes of vehicles, from miniature karts to huge trucks. The most popular races are A1Grand Prix, Le Man Series, Dakar rally, world championships in Formula-1, Formula-3, Formula-1600, GP2 and other classes.

For racing, in most countries, large sports complexes are being built, which include not only a modern track for auto and motorcycle races, but also a go-kart track, a technical park, as well as facilities that provide a comfortable, entertaining and versatile attractive stay for athletes (race participants) and visitors to the complexes both during the races and in the intervals between them. Several dozen different auto and motor sport races are held annually on such tracks.

Tracks for international races of the kart series, tracks for other types of races and races at the local level are currently built in Russia. For example, at the "Smolensk Ring" it is possible to hold circuit car races of all classes, except for "Formula-1". For several years now, the Russian Ministry of Sports has been negotiating the right to host the Grand Prix stage in the Formula-1 class of cars in our country. The tracks for their implementation are built on five continents. There are only 18 stages per year. At present, an international track has been built in Sochi; a similar route is under construction in Moscow.

At the same time, one should take into account a whole range of serious problems that need to be solved, in addition to the fact that the cost of the contract for the right to host the stage of the World Championship is very high. The arrangement of modern tracks that meet all Formula-1 racing standards is a complex technical task, for the solution of which the 
race organizers need serious financial resources, which can be obtained through attracting investors. However, this requires a detailed business plan, both for the construction of such a complex, and a justification of its economic attractiveness. It should be based, among other things, on who will be a potential consumer of the complex's services, how to find this consumer and sell the service to him, and how this consumer will be served during his stay on the highway [10].

One of the key points is the geographical choice of the construction site of the sports facility, so that tourists who come to Russia for the Formula 1 Grand Prix stage, in their free time from the competition, have the opportunity to visit cultural and historical attractions located at an accessible distance from the race venue. In turn, a system should be created that provides for the possibility, in addition to auto and motorcycle races, to include cultural events at facilities should include those located close to visiting a sports track, as well as tours, movement of visitors to other cultural and historical centers and recreational areas of Russia to or after a competition in an attractive type of motorsport for them.

The experience of creating a track for Formula 1 car races in Sochi can be successfully used in organizing similar sports events.

The technology of organizing competitions in this and a similar sport should include two most important components:

\subsection{Preparing the sports facility and organizing the competition}

A sports facility must comply with the technical standards for similar facilities of the WTO, competitions held on it and be an attractive recreational area for visiting by the public during free time from competitions.

Designers should arrange the stands in such a way as to provide the greatest possible view of the track while respecting the safety of visitors. The entire complex must harmoniously fit into the surrounding area, without violating its ecology.

A sports facility, from our point of view, should include a network of various shops, restaurants, cafes, bars, swimming pools, tennis courts, gymnasiums, baths, hotels, children's sports schools, attractions, workshops for minor repairs, maintenance and washing of spectators' cars, paid parking lots, etc., since it will be used both by athletes (participants in competitions), fans and spectators of races, and by other public visiting the complex as a recreational recreation area between competitions. Special consideration should be given to the system of residence of visitors to auto races.

One of the attractive aspects of the complex for motorsport lovers can be the opportunity to drive along the circuit or in rented cars, or even on their own. On the basis of the autodrome, both master classes of pilots for all comers and special driving courses can be held [11].

For parking of personal vehicles, paid guarded parking is organized around the stadium or within the perimeter of the track. A bus depot should be located near the track for buses bringing both individual fans and fans who came to the Grand Prix in an organized manner.

The main services of the sports complex, in our opinion, should include:

1. Service of interaction with the International Automobile Federation (FIA) and the teams participating in the competition. The service concludes an agreement with the FIA on the right to conduct one of the stages in any auto or motor sport. The contract considers the shape of the track required for the race stage, the types of technical services provided and technical requirements for them, the need to provide additional equipment, transport, and special equipment. Teams - participants are provided with the necessary information about the customs rules for the carriage of cars or motor vehicles, as well as the equipment necessary for its maintenance, and assistance is provided in carrying out all customs procedures. The service agrees the place of residence of the riders and team employees, the 
package of services provided to all race participants, resolves all organizational issues that arise during the preparation and conduct of the competition, including the departure of the teams.

2. The sales service interacts with the media, provides advertising to the sports facility, competitions, cultural events, etc., concludes agreements with organizations that ensure the attendance of the sports complex through the advance sale of tickets and the reception of visitors (incl. foreign) both at the competitions and in their free time.

This service also organizes the sale of tickets for car races to private fans, as well as the sale of tickets for any sports and cultural events that will be held at the sports facility, hotel reservations, etc.

3. Engineering and technical service. Its tasks include monitoring the serviceability of engineering communications and all technical means serving the sports facility, their maintenance and repair. This service should also be in charge of: a gas station, workshops for minor repair and maintenance of cars, a helipad, car wash, etc.

The technical support service of the competition should deal with the maintenance of boxes for racing cars, monitor the condition of the track and technical safety equipment. Her duties also include the evacuation of damaged racing cars on the track and fire safety.

4. The social service provides services for tourists in shops, restaurants, cafes, bars, hotels, swimming pools, other sports complexes, children's sports schools, attractions belonging to the sports facility, interacts with other service enterprises that are not part of the sports facility in order to provide quality service visitors. Provides communication services (telephone, Internet, etc.), provides conditions for the provision of emergency medical care in the event of injuries to athletes or various diseases among fans, which are possible with a mass crowd of people, and, if necessary, ensures their hospitalization. In addition, the service must provide a number of paid services to visitors to the sports facility.

5. Security service. Its main task is to control the order throughout the entire territory of the facility, to protect the facilities of the sports facility. The service also runs paid parking lots for spectators.

6. The task of the communal service includes cleaning the territory, ensuring cleanliness in the stands, on the territory and at the facilities of the sports facility.

\subsection{Attracting sports fans to the races as visitors.}

The sports facility sales service, either independently or through its agents, publishes information about upcoming competitions and offers various service options. The main options might be:

- visiting only the competition itself with a minimum set of related services;

- arrival at a sports destination in order to implement a cultural program with a visit to various museums and other attractions, which includes a visit to a car race in the class of cars or motorcycles of interest as one of their components of the trip;

- trips in which the Formula-1 track is visited between competitions and is one of the many cultural sites.

For fans who come to watch only the competition must be provided with:

- reception and accommodation at the place of residence;

- provision of tickets for the race in a company envelope with enclosed advertising materials about additional services that he can receive by visiting the track;

- accompaniment of fans by the company's employees to the place of the race with a parallel story about the history of the race, about the places where it was held;

- protective equipment against noise;

- accompaniment and meeting of fans at the entrance to the track; 
- delivery of fans back to their place of residence;

- by agreement, transfer of fans from the airport or train station to the place of residence and back;

- by prior order, for an additional fee, the following can be provided:

a) any tickets to the stands of the Formula-1 track;

b)hotel reservations for more nights;

c)entrance ticket to the competition for 3 days.

Additionally, it may be considered providing fans with various accessories, such as baseball caps, umbrellas and others, with their logo as advertising.

When organizing an event in which visiting a car race is one of the components of a big trip, visitors need to:

- to ensure their meeting;

- deliver to the place of residence;

- place at the place of residence;

- show the museums, theatres and other attractions declared on the tour;

- escort to the place of departure (airport, train station).

Since it is essential for a fan when purchasing such a package of services to attend a competition on a race track, the organizer must take into account the specifics of the race and the guest's desire not only to visit it, but also related events, and provide additional information about the services provided during the sports competition. ... These services may include an excursion along the track, the opportunity to take pictures in the car of the teams participating in the race, the opportunity to visit the teams' boxes, purchase exclusive souvenirs and others. If the track is located far from the place of residence, the organizer must provide a place for stopping and feeding the fans.

The organizer of the trip (sales service of the sports complex) with a visit to the track in the intervals between competitions, as one of the attractions, should, during the development of the route, think over the moment of visiting the track during the entire trip to the sports destination. On the day of visiting the track, fans are taken to the venue of the auto race with a parallel story about the sights that the road passes by, about the history of various competitions that are held on the track. A tour guide with whom a contract has been signed shows the objects located on the track and tells their technical characteristics, provides free time for photographing, visiting souvenir shops located in the sports facility.

It is also possible to organize individual trips in the intervals between competitions, in which it is advisable to include inspection of a sports facility, driving a sports car on the track, visiting a museum (if any) of the track, historical and cultural monuments located on the way to the area of the sports facility, souvenir shops, photography in sports cars, etc.

To carry out these trips, the sports complex sales service concludes agreements with hotels, excursion bureaus, transport companies, directorates of cultural facilities, on the provision of relevant services. She develops travel routines. When developing them, special attention should be paid to the quality control of the services provided, and responsibility for the quality of services provided by third-party providers should be envisaged. In general, it has been proven that the main aspect of the quality of a sporting event directly affects the behavioural intentions of visitors to the SED, while the quality of the destination itself partially mediates the relationship between the image of the destination and the behavioral intentions of potential tourists. The quality of a sporting event is related to the development of loyalty to the destination [12].

It's known that mass sports events are carried out at a facility located in a sports and entertainment destination, and represent a corresponding cluster in the development of a particular region. Consequently, to assess the efficiency of using a sports facility, it is necessary to take into account the indirect impact on the economy of the region of income from visitors to the sports facility. To solve these problems, it is advisable to use a matrix 
multiplier in the system of input-output balances, as well as a tax multiplier. The main sources of income of the sports complex and its costs are shown in Fig. 3.

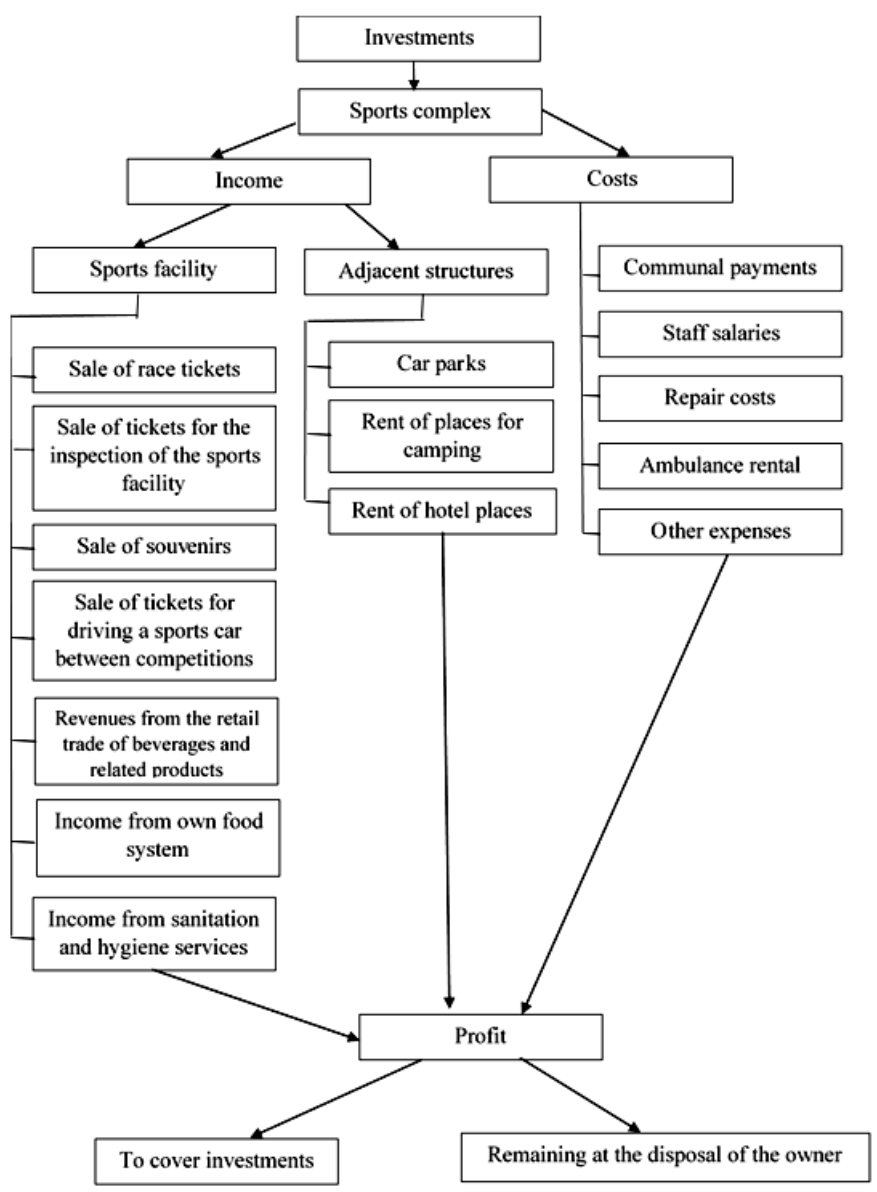

Fig. 3. Organizational and economic model for assessing the effectiveness of the organization of mass sports tourism events

The model, taking into account certain adjustments related to the specifics of the technology and organization of sports events, can be recommended for using the assessment of the effectiveness of the development of the sports industry as a whole.

It should also be emphasized that strong market competition and ever-increasing tourist needs are the reasons why the tourism industry is trying in various ways to offer original and exciting holiday experiences. However, the period of intuitive changes in the tourism economy is gradually coming to an end. It's time to move on to the next stage, characterized by professional animation of travel experiences. This raises new questions: What can be done to ensure that the travel experience is not completely random? [13] And here the integration of the system of sports and physical health improvement of a person with the tourism system in the format of a sports and entertainment destination will be very useful.

\section{Conclusion}

Conducted in a single complex, scientific studies of the methodology of tourist and sports activities have shown the identity of their functioning. Theoretical developments and 
methodological approaches developed in relation to the socio-economic system "Sport and physical recovery of a person" can be extended to tourism activities with minor adjustments. Scientific research of Russian and foreign scientists in the field of theory and methodology of the functioning of tourism and sports, as the most important social phenomena, not only confirmed the degree of complexity of the organization of tourist and sports activities, but also made it possible to identify the main measures to increase the effectiveness of the development of socio-economic systems "Tourism" and "Sport".

The most important of them are:

- development of a scientific and methodological concept for the study of their social essence and economic nature;

- study of their functioning in the conditions of an open commodity market and substantiation on this basis of the model of their gradual transition from the branches of management to the branches of the economy;

- search and modelling of organizational systems for managing innovative socioeconomic development at the federal, sub-industry and regional levels.

The presented developments, in their practical implementation, can contribute to solving one of the most important social tasks of the state - ensuring the health of the nation.

\section{Acknowledgements}

The authors express their deep gratitude to the honored worker of the high school, Professor Evgeny Bogdanov for an invaluable contribution to theoretical developments on the problem under study.

\section{References}

1. V. P. Kisedobrev, et al, Sports management (Publishing house of NSU im. P.F. Lesgaft, 2014)

2. V. M. Anipina, A. A. Dagaeva, Delo (2006)

3. E. T. Grebnev, Economics (2011)

4. L. Vodachek, O. Vodachkova, Economics (2011)

5. S. D. Ilyenkova, Banks and exchanges, (UNITI, 2014)

6. E. I. Bogdanov. Modern problems of theory and practice of management in elite sports (Publishing house of NSU im. P.F. Lesgaft, 2013)

7. E. I. Bogdanov, Tourism and sports (Publishing house of NSU im. P.F. Lesgaft, 2009)

8. Z. N. Kamilova, The mechanism for the formation of an integrated management system for sustainable development of the regional tourist complex (Makhachkala, 2011)

9. V. N. Gunin, V. P. Barancheev, V. A. Ustinov, S. Yu. Lyalina, Management of innovations (Infra-M, 2010)

10. V. P. Chistyakov, Service sector: management (KnoRus, 2012)

11. M. Sonder, Investment management: organization of entertainment events: techniques, ideas, strategies, methods (Vershina, 2006)

12. I. Milovanović, R. Matić, K. Alexandris, N. Maksimović, Z. Milošević, P. Drid, Journal of Hospitality \& Tourism Research, 10 (2019)

13. A. Stasiak, Creating and Managing Experiences in Cultural Tourism, 7 (2019) 